\title{
Predictive Stator Flux and Load Angle Control of Synchronous Reluctance Motor Drives Operating in a Wide Speed Range
}

\author{
Hazem Hadla and Sérgio Cruz, Senior Member, IEEE
}

\begin{abstract}
This paper presents a new simplified finitecontrol-set model predictive control strategy for synchronous reluctance motors operating in the entire speed range. It is a predictive control scheme that regulates the stator flux and the load angle of the synchronous reluctance motor, incorporating the ability to operate the drive in the field-weakening region and respecting the motor voltage and current limits as well as the load angle limitation needed to operate this type of motor in the maximum torque per voltage region. The proposed control strategy possesses some attractive features, such as no need for controller calibration, no weighting factors in the cost function, good robustness against parameter mismatch, and smaller computational cost compared to more traditional finite-control-set model predictive control algorithms.

Simulation and experimental results obtained using a high-efficiency synchronous reluctance motor demonstrate the effectiveness of the proposed control scheme.
\end{abstract}

Index Terms-Field-weakening operation, highperformance drives, model predictive control, synchronous reluctance motors.

\section{INTRODUCTION}

$\mathbf{T}$ $\mathrm{HE}$ advances in the rotor design of synchronous reluctance motors (SynRMs) lead to significant improvements in their performance, namely in the reduction of the torque ripple and increase of efficiency. In applications where a low motor price, high reliability, and fast dynamic response are important features, SynRMs are now looked as a serious alternative to induction motors (IMs) and permanent magnet synchronous motors (PMSMs) [1]. The absence of permanent magnet materials in the rotor makes SynRMs more cost effective than PMSMs of the same size. Moreover, SynRMs are particularly suited for high-speed applications, where the motor has to operate in the field-weakening (FW) region, as the maximum speed of a SynRM is limited solely by mechanical constraints rather than by the electric motor parameters [2].

Manuscript received July 22, 2016; revised October 25, 2016 and January 4, 2017; accepted March 7, 2017. Date of publication March 29, 2017; date of current version August 9, 2017. (Corresponding author: Sérgio Cruz.)

The authors are with the Department of Electrical and Computer Engineering, University of Coimbra, 3030-290 Coimbra, Portugal, and also with the Instituto de Telecomunicações, 1049-001 Lisbon, Portugal (e-mail: hrhadla@gmail.com; smacruz@ieee.org).

Color versions of one or more of the figures in this paper are available online at http://ieeexplore.ieee.org.

Digital Object Identifier 10.1109/TIE.2017.2688971
Traditionally, the control of motor drives and SynRM drives in particular, is based on strategies like field-oriented control (FOC) [3] and direct torque control (DTC) [4], [5]. More recently, model predictive control (MPC) has emerged as a powerful control method in the field of power electronics and motor drives, due to its intuitive concepts and simplicity, allowing at the same time to take into account several constraints in a very effective way. Due to these advantages, MPC has been proposed for the control of two- and three-level converters [6], [7], matrix converters [8], IM [9] and PMSM drives [10], among other applications.

Finite-control-set MPC (FCS-MPC) is nowadays the most popular type of MPC as it takes advantage of the discrete nature of the power converter, being the optimization problem inherent to MPC algorithms solved by the evaluation of a cost function for a finite number of possible actuations [11].

In [12], a predictive torque control strategy is presented for SynRMs. This algorithm, known as direct mean torque control, is a kind of DTC that calculates the switch-on time of the switches in a way that the steady-state value of the motor torque is reached at the end of the control cycle. In [13], a hierarchical direct predictive control strategy was proposed for SynRM drives. The main difference between this strategy and the conventional FCS-MPC algorithm lies in the process of obtaining the solution to the minimization problem, being the optimal voltage vector applied to the motor obtained from a hierarchical selection policy. In [14], an improved model-free predictive current control method is presented to control the current of the SynRM and to avoid the existence of current spikes that a model-based predictive current control method involves [15]. In [16], a simplified FCS-MPC algorithm was proposed for SynRMs, where the active flux and torque of the motor are the variables under control.

Very often the control systems based on FCS-MPC methods do not take into account the operation of the drive in the FW region. However, the torque and speed requirements of some applications, for instance traction drives, make this an important feature. The majority of the research work reported in the literature for the control of SynRMs and PMSMs able to operate in the FW region was developed considering FOC and DTC strategies [4], [5], [17]-[19]. The direct-flux vector control (DFVC), whose control system regulates directly the stator amplitude and torque (through the control of the $q$-axis current) in a stator-flux-oriented reference frame was proposed to 
control SynRMs in a wide speed range [20], [21]. In the DFVC system, two proportional-integral (PI) regulators are required to regulate the stator flux and the $q$-axis current plus a third PI regulator to handle the operation of the drive in the maximum torque per voltage (MTPV) region, which occurs when the motor pull-out torque has been reached and the load angle has to be limited to avoid system instabilities. Of course, the use of PI controllers always involves some tuning effort which ideally should be avoided. Having this in mind, Boazzo and Pellegrino [22] presented a model-based version of the DFVC for PMSM drives, which avoids the use of PI regulators by generating the inverter reference voltages from the flux linkage and $q$-axis current set points, using an elaborated inverse motor model.

To this date, the development of FCS-MPC strategies for synchronous motor drives able to operate in the FW region is very scarce. In [23], a FCS-MPC strategy was developed for PMSMs in order to achieve optimal performance and ability to operate in the FW region. Nonetheless, the cost function used has three terms in order to take into account different criteria, each term having a weighting factor; hence, requiring again significant tuning effort which is still considered one of the complex tasks of FCS-MPC algorithms. As far as FCS-MPC strategies specifically proposed for SynRM drives, no work has been reported yet in the literature.

This paper proposes a novel FCS-MPC strategy for SynRM drives, able to operate in the entire speed range: constant torque region, constant power region, and MTPV region (constant load angle region). The proposed control structure ensures an excellent dynamic performance and a smooth transition between the different operation regions. Moreover, it exhibits a high robustness against motor parameter variations. In addition to these aspects, the proposed control system relies on a simplified version of the traditional FCS-MPC algorithms, where a reference voltage vector is generated, thus avoiding the use of weighting factors in the cost function.

The main contributions of this paper can be summarized as follows: 1) control system with no PI regulators; 2) the MTPV limit is tackled with a very simple saturation block; 3 ) the cost function does not need any weighting factors; and 4) the reference voltages are obtained in a direct manner using the motor model in a reference frame aligned with the stator flux vector, without any modification, on contrary to what was done in [22].

\section{Mathematical Model of the SynRm}

The control system proposed in this study is based on the direct control of the motor stator flux $\psi_{s}$ and load angle $\delta$, using a reference frame aligned with the stator flux vector, labeled as $d_{s} q_{s}$ in Fig. 1. The $d q$ rotor reference frame is used in the current model of the stator flux and load angle observer and to estimate the motor inductances, as detailed later on.

The voltage equations of the SynRM in the $d_{s} q_{s}$ reference frame are given by

$$
u_{d s}=R_{s} i_{d s}+\frac{d \psi_{s}}{d t}
$$

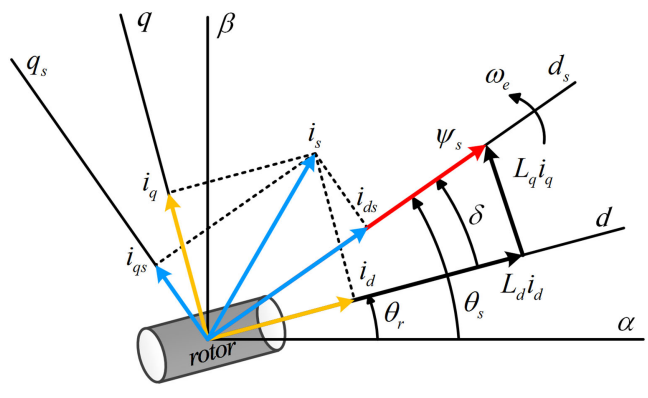

Fig. 1. Reference frames used in the analysis of the SynRM.

$$
u_{q s}=R_{s} i_{q s}+\left(\frac{d \delta}{d t}+\omega_{r}\right) \psi_{s}
$$

where $u_{d s}, u_{q s}, i_{d s}, i_{q s}$ are the $d_{s}$-axis and $q_{s}$-axis components of the stator voltages and currents, respectively, $R_{s}$ is the stator winding resistance, $\psi_{s}$ is the stator flux linkage, and $\omega_{r}$ is the electric angular rotor speed.

The instantaneous angular supply frequency $\omega_{e}$ is related to $\omega_{r}$ by

$$
\omega_{e}=\frac{d \delta}{d t}+\omega_{r}
$$

Of course, in steady-state conditions, $\omega_{e}=\omega_{r}$. In transient conditions and considering a discretization time step relatively small, which is always the case when dealing with predictive control algorithms, the approximation $\omega_{e} \simeq \omega_{r}$ does not introduce any significant errors and will be considered.

The electromagnetic torque can be expressed as a function of the load angle by

$$
T_{e}=\frac{3}{4} p\left(\frac{1}{L_{q}\left(i_{d}, i_{q}\right)}-\frac{1}{L_{d}\left(i_{d}, i_{q}\right)}\right) \psi_{s}^{2} \sin 2 \delta=\frac{3}{2} p \psi_{s} i_{q s}
$$

where $L_{d}, L_{q}$ represent the apparent inductances of the stator windings and $p$ is the number of pole pairs. To take into account the saturation and cross-magnetic saturation in the SynRM, the apparent inductances are here considered a function of both current components in a rotor reference frame. The apparent inductance values can be obtained offline and stored in 2-D lookup tables or estimated online. This subject will be addressed in more detail in the next section.

\section{Predictive Stator Flux and Load Angle Control}

\section{A. Proposed Control System}

The proposed predictive control system relies on a FCS strategy which ensures that the stator flux magnitude and load angle of the SynRM follow the corresponding reference values. The choice of the load angle as a control variable instead of the electromagnetic torque has some advantages, namely to ensure a smooth transition between the operation of the drive in the constant power region and MTPV region, as discussed later on. 


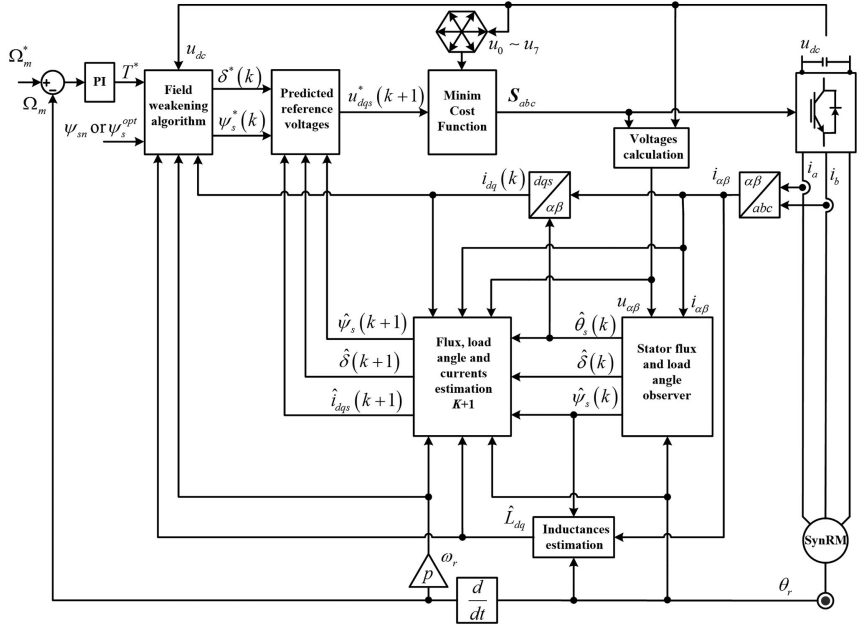

Fig. 2. Proposed predictive stator flux and load angle control system for SynRM drives.

A general diagram of the proposed control system is shown in Fig. 2, being described in more detail in the following subsections.

1) Prediction Model: By choosing $\psi_{s}$ and $\delta$ as state variables, (1), (2) can be rewritten as

$$
\begin{aligned}
\frac{d \psi_{s}}{d t} & =u_{d s}-R_{s} i_{d s} \\
\frac{d \delta}{d t} & =\frac{u_{q s}-R_{s} i_{q s}}{\psi_{s}}-\omega_{r} .
\end{aligned}
$$

These equations, after discretization using a forward Euler algorithm, allow to obtain the estimated values of $\psi_{s}$ and $\delta$, for instant $k+1$

$$
\begin{aligned}
& \hat{\psi}_{s}(k+1)=\hat{\psi}_{s}(k)+T_{s}\left[u_{d s}(k)-R_{s} i_{d s}(k)\right] \\
& \hat{\delta}(k+1)=\hat{\delta}(k)+\frac{T_{s}}{\hat{\psi}_{s}(k)}\left[u_{q s}(k)-R_{s} i_{q s}(k)-\omega_{r} \hat{\psi}_{s}(k)\right] .
\end{aligned}
$$

In the equations above, $T_{s}$ is the sampling period and the estimated quantities $\hat{\psi}_{s}(k)$ and $\hat{\delta}(k)$ are obtained with a stator flux and load angle observer.

As with any conventional FCS-MPC strategy, the actuation delay of one sampling period would lead to the necessity of predicting the values of the state variables for the sampling instant $k+2$, considering all possible voltage vectors that can be applied to the motor by inverter (seven different voltage vectors in the case of a two-level inverter) [24]. Nevertheless, a simplified FCS-MPC algorithm proposed for two-and three-level power converters in [25] and [26], and more recently adapted to SynRM drives [16], can avoid this procedure. The idea of this algorithm is to reduce the computation time by eliminating the need of the seven predictions and calculate instead the reference voltage vector $u^{*}(k+1)$ that applied to the motor at instant $k+1$ would force the state variables to reach the corresponding reference values at instant $k+2$.

Adopting a similar concept here, it is considered that the reference values of $\psi_{s}$ and $\delta$, calculated at the sampling instant $k$ by the FW algorithm, are reached by the system at instant $k+2$. This is equivalent to establish the following relations

$$
\begin{aligned}
\psi_{s}(k+2) & =\psi_{s}^{*}(k) \\
\delta(k+2) & =\delta^{*}(k) .
\end{aligned}
$$

Taking into account (9), (10), and the discretization of (5), (6), for instant $k+1$, and solving the obtained equations for the voltage components at instant $k+1$, yields

$$
\begin{aligned}
u_{d s}^{*}(k+1)= & R_{s} \hat{i}_{d s}(k+1)+\left(\frac{\psi_{s}(k+2)-\hat{\psi}_{s}(k+1)}{T_{s}}\right) \\
u_{q s}^{*}(k+1)= & R_{s} \hat{i}_{q s}(k+1)+\frac{\hat{\psi}_{s}(k+1)}{T_{s}} \\
& \times(\delta(k+2)-\hat{\delta}(k+1))+\omega_{r} \hat{\psi}_{s}(k+1) .
\end{aligned}
$$

The predicted current values needed for the calculation of the reference voltages in (11) and (12) are first estimated for instant $k+1$, in a rotor reference frame, by solving

$$
\begin{aligned}
\hat{i}_{d}(k+1)= & i_{d}(k)+\frac{T_{s}}{L_{d}^{\text {inc }}}\left[u_{d}(k)-R_{s} i_{d}(k)+\omega_{r} \hat{L}_{q} i_{q}(k)\right] \\
& +\frac{L_{d q}^{\text {inc }}}{L_{d}^{\text {inc }}}\left(i_{q}(k)-\hat{i}_{q}(k+1)\right) \\
\hat{i}_{q}(k+1)= & i_{q}(k)+\frac{T_{s}}{L_{q}^{\text {inc }}}\left[u_{q}(k)-R_{s} i_{q}(k)-\omega_{r} \hat{L}_{d} i_{d}(k)\right] \\
& +\frac{L_{d q}^{\text {inc }}}{L_{q}^{\text {inc }}}\left(i_{d}(k)-\hat{i}_{d}(k+1)\right)
\end{aligned}
$$

and, subsequently, transformed to the stator flux reference frame by

$$
\left\{\begin{array}{c}
\hat{i}_{d s}(k+1)=\cos \hat{\delta}(k+1) \hat{i}_{d}(k+1) \\
+\sin \hat{\delta}(k+1) \hat{i}_{q}(k+1) \\
\hat{i}_{q s}(k+1)=-\sin \hat{\delta}(k+1) \hat{i}_{d}(k+1) \\
+\cos \hat{\delta}(k+1) \hat{i}_{q}(k+1)
\end{array} .\right.
$$

In (13) and (14), the superscript "inc" is used to denote incremental inductances.

The final stage of the simplified FCS-MPC algorithm is the choice of the actuation voltage vector at instant $k+1$, which is selected based on the minimization of a very simple cost function $g$ representing the square of the Euclidean distance between the reference voltage vector, whose components are given by (11), (12), and each one of the voltage vectors that the inverter can apply to the motor

$$
\begin{aligned}
& g=\left|u_{d s}^{*}(k+1)-u_{d s n}\right|^{2}+\left|u_{q s}^{*}(k+1)-u_{q s n}\right|^{2}, \\
& n=0,1, . .6 .
\end{aligned}
$$

The simplified FCS-MPC strategy requires less computation time compared to more traditional FCS-MPC approaches as instead of seven predictions for the stator flux and load angle, 


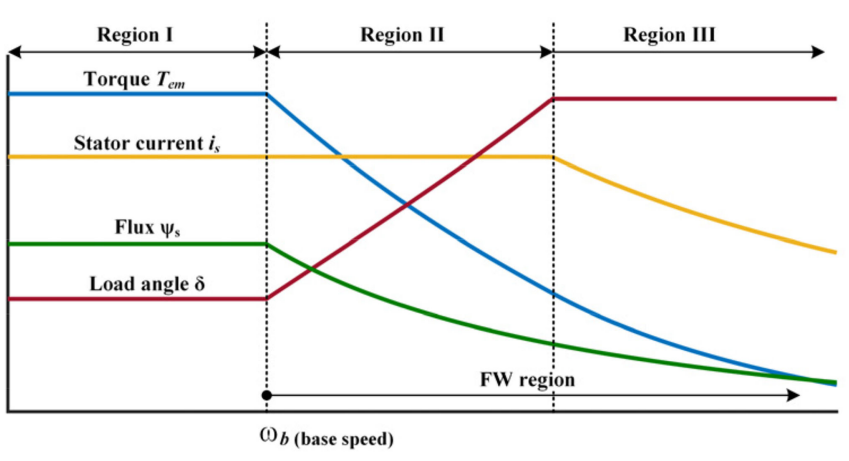

Fig. 3. Regions and limits of operation of a SynRM drive.

a reference voltage vector is calculated only once and a much simpler cost function is evaluated at the end, without the need to tune any weighting factor.

It should be noted, however, that similarly to other traditional FCS-MPC strategies, the proposed cost function leads to a variable switching frequency of the inverter. This may be undesirable in certain applications (e.g., due to the need to reduce the switching losses, in order to reduce the cooling requirements of the inverter; when using output $\mathrm{dv} / \mathrm{dt}$ filters in the inverter, etc.). The switching frequency is higher when the drive runs at very low speeds, during which it can reach the maximum theoretical limit of $1 /\left(2 T_{s}\right)$. The reduction of the switching frequency can be achieved by including an additional term in the cost function [6]. Due to the limited space available, this topic is not addressed in detail in this paper, being the cost function used the one presented in (16).

2) FW Operation: The operation of the drive in the entire speed range, including $\mathrm{FW}$, is here considered.

As far as speed is concerned, the SynRM drive can operate in three different regions: region I (constant torque region), where the motor is able to develop rated torque, and operation in the FW region, which comprises region II (constant power region) and region III (MTPV region) (see Fig. 3).

In region I, below base speed, the stator current has to be limited due to the thermal constraints of the motor and inverter. When the base speed is reached, the motor voltage is the rated one and it cannot be increased further, hence the stator flux has to be reduced with the increase of speed and the drive enters into region II. In this region, because the maximum current is the rated value but the stator flux is inversely proportional to speed, the maximum torque developed by the motor will be inversely proportional to speed as well, while the maximum power is still the rated one. The load angle in this region increases with speed until, at very high speeds, it reaches the stability limit of $\delta=45 \mathrm{deg}$. From this point on, the load angle cannot be increased further to ensure drive stability and this is the additional restriction for the operation of the drive in region III (MTPV region). It should be noted that on the contrary to PMSMs, the maximum speed of a SynRM will be limited solely by the load torque or by mechanical constraints. From the electrical point of view, the maximum speed of the drive would be infinity.

Fig. 4 presents a block diagram illustrating how the different limitations are imposed by the control system, ensuring

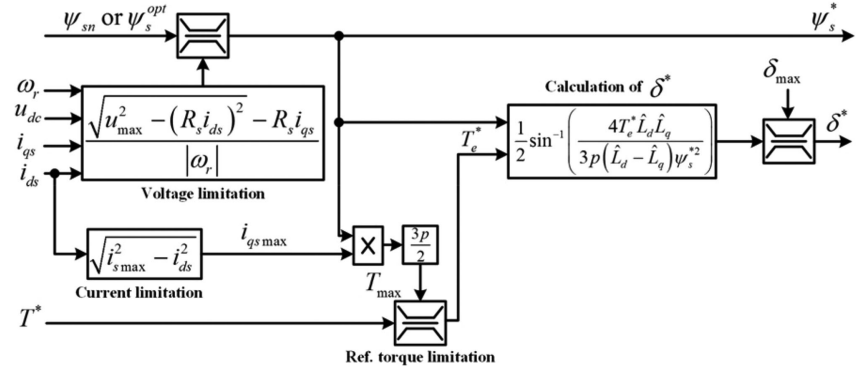

Fig. 4. Limits of operation and generation of the reference quantities in the proposed predictive control system.

the stable and safe operation of the drive in the entire speed range.

The reference value of the stator flux is the rated one (or an optimum flux level, as detailed later on in Section III-A4) until the stator voltage limit $u_{\max }$ is reached. The limit is the minimum value between the maximum output voltage the inverter can produce from the available dc-link voltage $u_{\mathrm{dc}}\left(u_{\max }=u_{\mathrm{dc}} / \sqrt{3}\right)$, and the rated voltage of the motor (which will be case of the SynRM used in the experimental tests, as it has a rated voltage smaller than the maximum available voltage). In mathematical terms, this is equivalent to set the reference flux as [27]

$$
\psi_{s}^{*}=\frac{\sqrt{u_{\max }^{2}-\left(R_{s} i_{d s}\right)^{2}}-R_{s} i_{q s}}{\left|\omega_{r}\right|} .
$$

In regions I and II, the current has to be limited at all times to a maximum value $i_{s \max }$. The current component $i_{d s}$ is responsible for the magnetization of the motor, hence the current limit must be imposed on the $q_{s}$-axis current component

$$
i_{q s \max }=\sqrt{i_{s \max }^{2}-i_{d s}^{2}} .
$$

This limit will be translated into a maximum torque the motor can develop, given by

$$
T_{\max }=\frac{3}{2} p \psi_{s}^{*} i_{q s \max } .
$$

The above limitations, in conjunction, ensure the safe operation of the drive in regions I and II.

The reference value of the load angle $\delta^{*}$ is needed in the predictive control algorithm. Moreover, it has to be limited when the drive enters into region III.

The reference load angle is calculated by

$$
\delta^{*}=\frac{1}{2} \sin ^{-1}\left[\frac{4 T_{e}^{*} \hat{L}_{d} \hat{L}_{q}}{3 p\left(\hat{L}_{d}-\hat{L}_{q}\right) \psi_{s}^{* 2}}\right]
$$

where $T_{e}^{*}$ is either the reference torque set by the user (drive operating in torque control mode) or the torque generated by the speed controller, after passing through the torque limitation block. This load angle must then be limited to an appropriate maximum value to ensure a smooth transition between regions II and III and to guarantee at the same time the stability of the drive in region III. Usually, with other control approaches, like in [20] and [21], the load angle is limited with the aid of a PI regulator. 


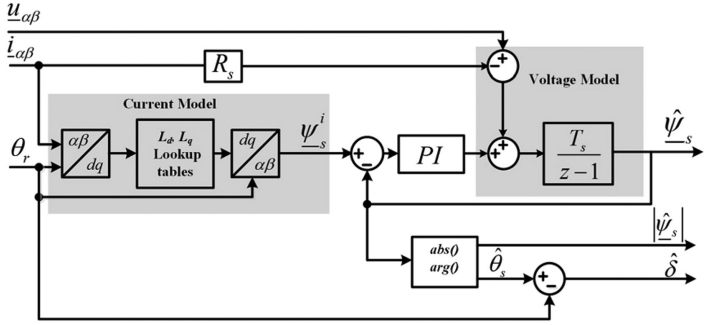

Fig. 5. Stator flux and load angle observer.

Here, instead, as the load angle is directly controlled, it is very easy to limit the reference load angle by a simple saturation block with a specified limit $\delta_{\max }$. If full-drive capabilities are to be explored, this limit should be set to $\delta_{\max }= \pm 45 \mathrm{deg}$, where the positive and negative values apply to the cases when the machine operates as a motor or generator, respectively.

3) Stator Flux and Load Angle Observer: The control system uses a hybrid stator flux observer, which comprises a voltage model and a current model of the SynRM, as shown in Fig. 5.

The current model allows to estimate reliably the stator flux at low speeds and uses the values of the motor inductances, measured offline and stored in 2-D lookup tables, while the voltage model dominates at medium and high speeds, allowing to estimate the stator flux in those regions in a way almost independent of the errors that may exist in the values of the motor inductances. To improve the accuracy of the voltage model, the deadtime of the inverter is compensated in the calculation of voltages $\underline{u}_{\alpha \beta}$ using a procedure identical to the one presented in [28].

The flux observer provides the amplitude $\hat{\psi}_{s}$ and the phase angle $\hat{\theta}_{s}$ of the stator flux. The load angle $\hat{\delta}$ is estimated as the difference between the flux phase angle and the measured electrical rotor position $\theta_{r}$.

4) Stator Flux Level Optimization: The control system proposed in this paper is aimed at obtaining a high-performance drive, with a very good torque response. That is achieved if the stator flux level is maintained at its rated value, independently of the motor load level. However, in certain applications, it may be preferable to operate the drive such that the motor copper losses are minimized. This is achieved if, for a given torque demand, the current amplitude is minimized. The condition corresponding to the maximum torque to current ratio is usually known as the maximum torque per ampere (MTPA) trajectory. In current-controlled systems, the implementation of the MTPA trajectory is more or less straightforward. With the proposed control system, the MTPA trajectory has to be translated into an optimal stator flux reference value, thus requiring some additional analytical work.

Let us consider an equivalent circuit of the SynRM, in a rotor reference frame and including the iron losses, represented by the iron losses resistance $R_{c}$. It can be shown that the power losses in the motor are given by

$$
P_{e}=\frac{3}{2} \frac{u_{s}^{2}}{R_{s}+R_{c}}+\frac{3}{2} \frac{R_{s} R_{c}}{R_{s}+R_{c}}\left[\left(\frac{\psi_{d}}{\hat{L}_{d}}\right)^{2}+\left(\frac{\psi_{q}}{\hat{L}_{q}}\right)^{2}\right] .
$$

The previous equation contains a first term that roughly represents the iron losses, and a second one that is directly related to the stator copper losses. The motor used in this study is a high efficiency one, therefore, and for the sake of simplicity, the first term will be neglected and it is considered that only the losses given by the second term can be minimized. Let us now define $M$ as

$$
M=\left(\frac{\psi_{d}}{\hat{L}_{d}}\right)^{2}+\left(\frac{\psi_{q}}{\hat{L}_{q}}\right)^{2} .
$$

In a rotor reference frame, the electromagnetic torque developed by the SynRM can be given by

$$
T_{e}=\frac{3}{2} p\left(\frac{1}{\hat{L}_{q}}-\frac{1}{\hat{L}_{d}}\right) \psi_{d} \psi_{q} .
$$

By solving (23) for $\psi_{q}$ and using the result in (22), one can write $M$ as a function of $\psi_{d}$. The value of $\psi_{d}$ that minimizes $M$ is obtained by solving $\partial M / \partial \psi_{d}=0$, yielding

$$
\psi_{d}^{\mathrm{opt}}=\hat{L}_{d} \sqrt[4]{\frac{4 T_{e}^{2}}{9 p^{2}\left(\hat{L}_{d}-\hat{L}_{q}\right)^{2}}} .
$$

The optimal value $\psi_{d}^{\mathrm{opt}}$ is calculated using (24) considering $T_{e}=T^{*}$. The optimal value $\psi_{q}^{\mathrm{opt}}$ is then calculated using that result in (23). With these two flux components, the optimal stator flux level used in the control system (see Fig. 4) can be calculated by $\psi_{s}^{\mathrm{opt}}=\sqrt{\left(\psi_{d}^{\mathrm{opt}}\right)^{2}+\left(\psi_{q}^{\mathrm{opt}}\right)^{2}}$.

\section{B. Parameters Mismatch}

In MPC algorithms, the accuracy of the motor parameters is of paramount importance to achieve a superior performance with regard to drive stability, high motor efficiency, low-current ripple, and good motor tracking of the reference values set by the controller. This is particularly important when dealing with a SynRM where saturation and cross-magnetic saturation are nonnegligible phenomena, affecting directly the values of the motor inductances.

When dealing with the motor inductances, one has to distinguish two types of inductances used by the control system: 1) incremental inductances, used in (13) and (14), and 2) apparent inductances used in (13), (14), and (20).

The values of the incremental inductances govern the transient behavior of the motor and are defined as the slope of the tangent to the flux maps, at the considered operating point.

By definition, the incremental inductances are given by

$L_{d}^{\mathrm{inc}}=\frac{\partial \psi_{d}\left(i_{d}, i_{q}\right)}{\partial i_{d}}, L_{q}^{\mathrm{inc}}=\frac{\partial \psi_{q}\left(i_{d}, i_{q}\right)}{\partial i_{q}}, L_{d q}^{\mathrm{inc}}=\frac{\partial \psi_{d}\left(i_{d}, i_{q}\right)}{\partial i_{q}}$.

On the other hand, the apparent inductances, at the considered operating point, are given by

$$
L_{d}=\frac{\psi_{d}\left(i_{d}, i_{q}\right)}{i_{d}}, L_{q}=\frac{\psi_{q}\left(i_{d}, i_{q}\right)}{i_{q}} .
$$

In this study, the values of the apparent inductances $L_{d}$ and $L_{q}$ are stored in 2-D lookup tables obtained offline. Based on these tables, the incremental inductances used by the control system, 
at the operating point $\left(i_{d}, i_{q}\right)=\left(i_{d 0}, i_{q 0}\right)$, are calculated using the approximate relations

$$
\left\{\begin{array}{l}
L_{d}^{\mathrm{inc}} \simeq \frac{\psi_{d}\left(i_{d 0}+0.2, i_{q 0}\right)-\psi_{d}\left(i_{d 0}, i_{q 0}\right)}{0.2} \\
L_{q}^{\mathrm{inc}} \simeq \frac{\psi_{q}\left(i_{d 0}, i_{q 0}+0.2\right)-\psi_{q}\left(i_{d 0}, i_{q 0}\right)}{0.2} \\
L_{d q}^{\mathrm{inc}} \simeq \frac{\psi_{d}\left(i_{d 0}, i_{q 0}+0.2\right)-\psi_{d}\left(i_{d 0}, i_{q 0}\right)}{0.2}
\end{array}\right.
$$

In the proposed control strategy, errors introduced in the values of the incremental inductances lead to errors in the values of the predicted currents for instant $k+1$ but they do not affect the motor steady-state tracking capability of the reference values set by the control system. Several simulation and experimental tests have shown that the sole effect of incremental inductance errors as high as $40 \%$ is the increase of current and torque ripples, without affecting the steady-state performance of the drive system. Hence, considering these results, no error compensation mechanism was included for the values of the incremental inductances.

On the other hand, the apparent inductance errors have a much higher influence on the performance of the proposed control system. The values of $L_{d}$ and $L_{q}$, stored in the 2-D lookup tables and used by the current model of the stator flux observer, are inevitably affected by some uncertainty, being the source of some errors in the estimated stator flux and load angle values in the low-speed region. In the medium- and high-speed regions, the voltage model stands, almost eliminating the influence of inductance values mismatch in the outputs of the stator flux and load angle observer.

The inductance values are also used in the current prediction equations and, more importantly, in the calculation of the reference load angle using (20). In the first case, the inductance values mismatch does not affect significantly the operation of the drive, as the currents are neither directly controlled nor evaluated in the cost function. On the contrary, the calculation of the reference load angle is significantly affected by the inductances errors, especially the error in $L_{q}$, leading the SynRM drive to operate with a torque and a load angle quite different from the ones set by the control system. To minor these effects, the prediction model and the reference load angle generation block use inductance values estimated online by

$$
\hat{L}_{d}=\frac{\hat{\psi}_{d}}{i_{d}}, \hat{L}_{q}=\frac{\hat{\psi}_{q}}{i_{q}}
$$

with all variables expressed in a rotor reference frame. Both inductances can be reliably estimated as long as the currents have a reasonable minimum value, say $1 \mathrm{~A}$, to avoid divisions by zero or estimated inductance profiles with a high-noise content. In practice, $i_{d}$ is always much higher than this minimum value, allowing the estimation of $\hat{L}_{d}$ at all times, while the estimation of $\hat{L}_{q}$ has to be disabled when the motor operates at very low-load levels, using in those cases the values stored in the corresponding lookup table.

The changeover between the estimated value $\hat{L}_{q}$ and the one obtained with the lookup table $\left(L_{q}^{\mathrm{LUT}}\right)$ needs to be gradual and smooth in order to prevent any instability or bumps in the operation of the SynRM. The transition process was

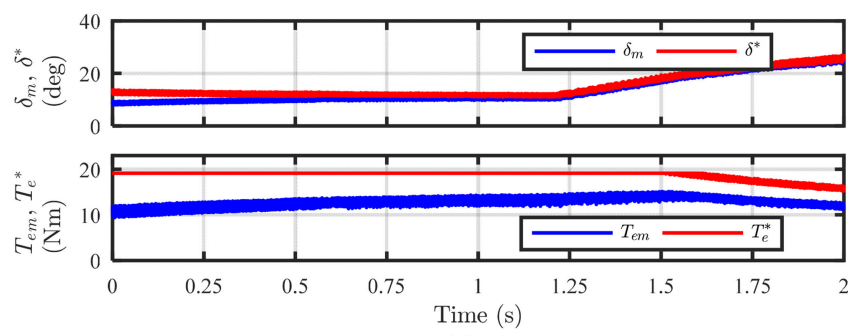

(a)

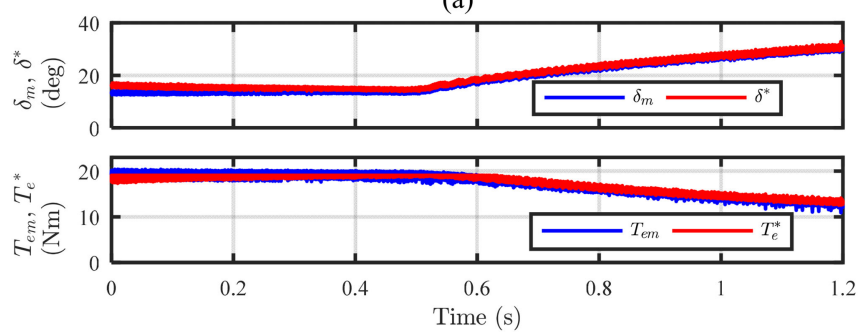

(b)

Fig. 6. Simulated results for the reference load angle and electromagnetic torque set by the control system (red plots) versus the corresponding motor quantities (blue plots) when the SynRM drive is accelerating with a load torque of $5 \mathrm{~N} \cdot \mathrm{m}$ and with $-20 \%$ detuning in $L_{d}$ and $L_{q}$. (a) Without inductance estimation (speed range: 450 to $2550 \mathrm{r} / \mathrm{min}$ ). (b) With inductance estimation (speed range: 450 to $2440 \mathrm{r} / \mathrm{min}$ ).

implemented according to the following conditions

$L_{q}=$

$\begin{cases}L_{q}^{\mathrm{LUT}} & ;\left|i_{q}\right|<i_{q}^{\text {tra }} \\ L_{q}^{\mathrm{LUT}}\left(1-\frac{\left|i_{q}\right|-i_{q}^{\mathrm{tra}}}{\Delta i_{q}}\right)+\hat{L}_{q} \frac{\left|i_{q}\right|-i_{q}^{\mathrm{tra}}}{\Delta i_{q}} & ; i_{q}^{\text {tra }} \leq\left|i_{q}\right| \leq i_{q}^{\text {tra }}+\Delta i_{q} \\ \hat{L}_{q} & ;\left|i_{q}\right|>i_{q}^{\text {tra }}+\Delta i_{q}\end{cases}$

where $i_{q}^{\text {tra }}=1 \mathrm{~A}, \Delta i_{q}=0.2 \mathrm{~A}$.

In order to illustrate the importance of estimating the values of the apparent inductances, Fig. 6 shows some simulation results obtained with an error of $-20 \%$ introduced in both inductance values used by the control system. As can be seen, without the online inductance estimation procedure, the torque and load angle of the motor is much lower than the reference values set by the control system, which may even prevent the drive from starting if the starting load torque is high. When the inductance online estimation procedure is activated, the control and actual motor variables are much closer, allowing to operate satisfactorily the drive in the entire speed range, thus increasing significantly the robustness of the control system to parameter uncertainties.

It must be highlighted here that under the presence of a positive error in the apparent inductances, if no online inductance estimation procedure was used, the control system would not be able to limit the motor current to the maximum value $i_{s \max }$ used in (18). Hence, the online inductance estimation procedure also plays an important role in the current limitation process.

Besides the errors in the motor inductances, it is known that due to motor temperature variations, the stator resistance varies 


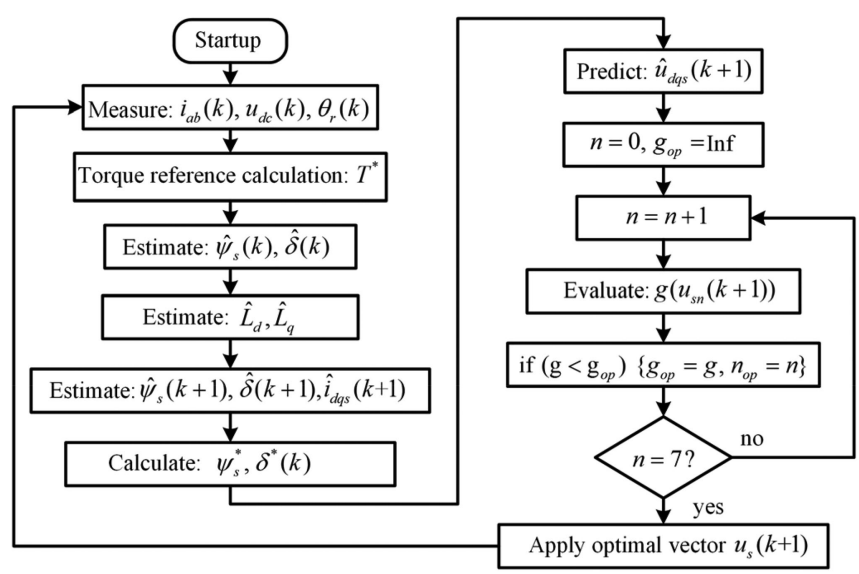

Fig. 7. Main steps involved in the implementation of the control algorithm.

TABLE I

SYNRM DRIVE PARAMETERS

\begin{tabular}{lccc}
\hline \hline Rated power & $3 \mathrm{~kW}$ & Rated torque & $19.1 \mathrm{~N} \cdot \mathrm{m}$ \\
Rated voltage & $355 \mathrm{~V}$ & Rated speed & $1500 \mathrm{r} / \mathrm{min}$ \\
Rated current & $7.9 \mathrm{~A}$ & Rated efficiency & $90.4 \%$ \\
Rated frequency & $50 \mathrm{~Hz}$ & Rated stator flux & $0.923 \mathrm{~Wb}$ \\
Rated dc-link voltage & $560 \mathrm{~V}$ & Sampl. period $T_{s}$ & $40 \mu \mathrm{s}$ \\
Speed loop & & $K_{p}$ & 0.15 \\
& & $T_{i}$ & 0.66 \\
\hline \hline
\end{tabular}

over time. The error in value of the stator resistance used by the control system affects mainly the voltage model of the stator flux estimator at low speeds. Nevertheless, in the proposed control system, a hybrid flux estimator is used, where the current model dominates at low speeds. For this reason, in this paper, no stator resistance variation compensation mechanism is proposed. Nevertheless, if desired, the flux observer used here can be extended by including a stator resistance adaptation law, similar to one presented in [29] for salient PMSMs.

This section ends with the presentation in Fig. 7 of a flowchart containing the main steps involved in the implementation of the proposed control system.

\section{Obtained Results}

The performance of the proposed control system was verified with a SynRM drive operating in different conditions, using a simulation model implemented in Simulink, and an experimental setup.

The nameplate data of the SynRM used in the tests and some control parameters are listed in Table I.

The experimental setup consists in a dSPACE 1103 platform to control the SynRM drive system, which comprises a high-efficiency (IE4) SynRM, coupled to an auxiliary 7.5-kW induction motor fed by an inverter to act as a controlled mechanical load. An incremental encoder of 1024 ppr, a Yokogawa WT3000 precision power analyzer, and a torque sensor complement the setup.

The values of the apparent inductances stored in the 2-D lookup tables were obtained offline using the VI method
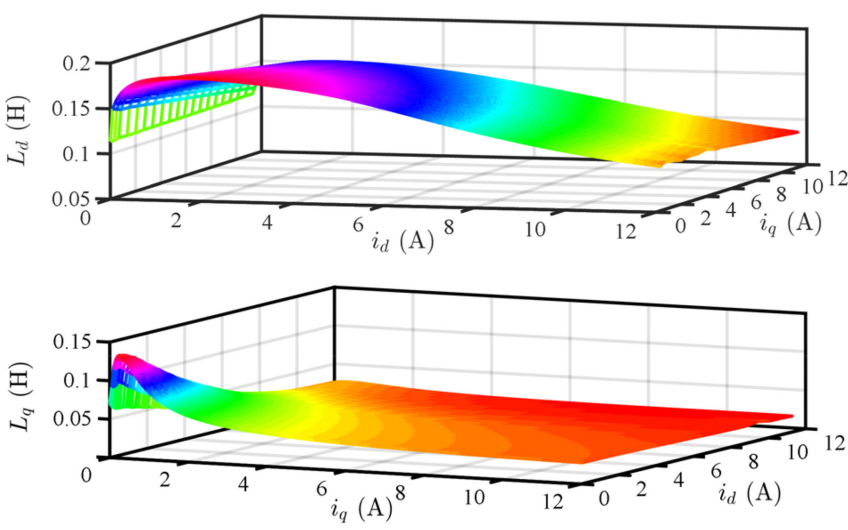

Fig. 8. Apparent inductances of the SynRM used in the simulation model and in the experimental tests.

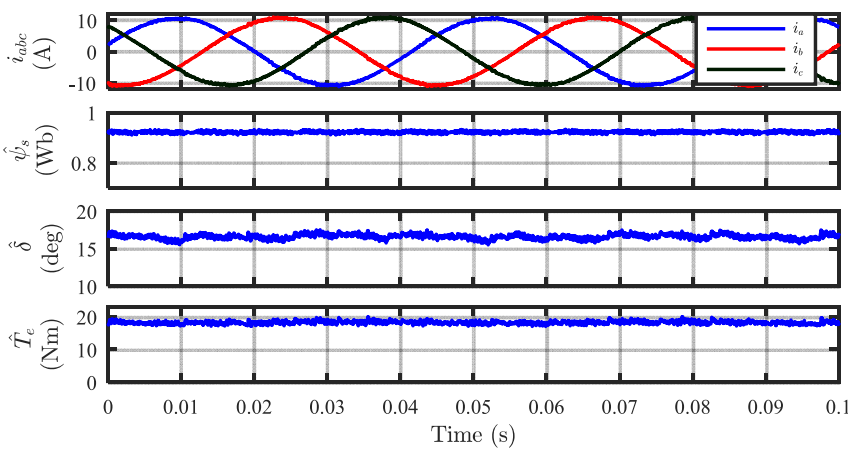

Fig. 9. Experimental results for the steady-state operation of the SynRM at a speed of $700 \mathrm{r} / \mathrm{min}$ with rated load torque.

mentioned in [30]. According to this method, one winding is supplied by a controllable dc source, while the other two windings, series connected, are supplied by a variable ac voltage source. The tests were conducted at different current values and with the rotor in two fixed positions: along the $d$-axis and along the $q$-axis of the stator windings. Hence, the inductances measured take into account the saturation and cross-magnetic saturation of the SynRM, phenomena quite evident in the obtained results shown in Fig. 8.

\section{A. Constant Torque Operation}

In this section, the proposed control system is validated in the constant torque region. For this purpose, three different conditions are analyzed: steady-state operation, speed reversal maneuver, and torque step response. In these three tests, the dc-link voltage was set to the rated value.

Fig. 9 shows the experimental results obtained for the steadystate operation of the SynRM drive, operating at $700 \mathrm{r} / \mathrm{min}$ with rated load torque.

The results show that the motor currents are almost sinusoidal, with a very small total harmonic distortion factor (THD $=0.95 \%$ ). The stator flux is almost constant and follows with precision the reference value. The load angle and the electromagnetic torque exhibit low ripples, if compared with 


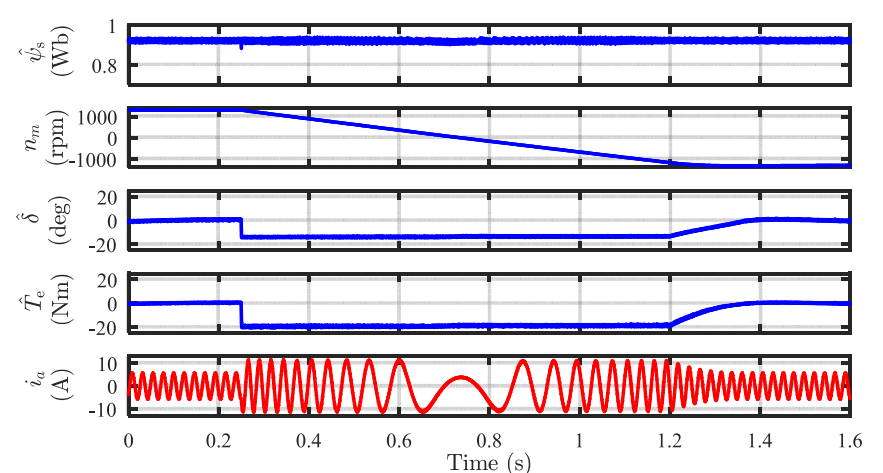

(a)
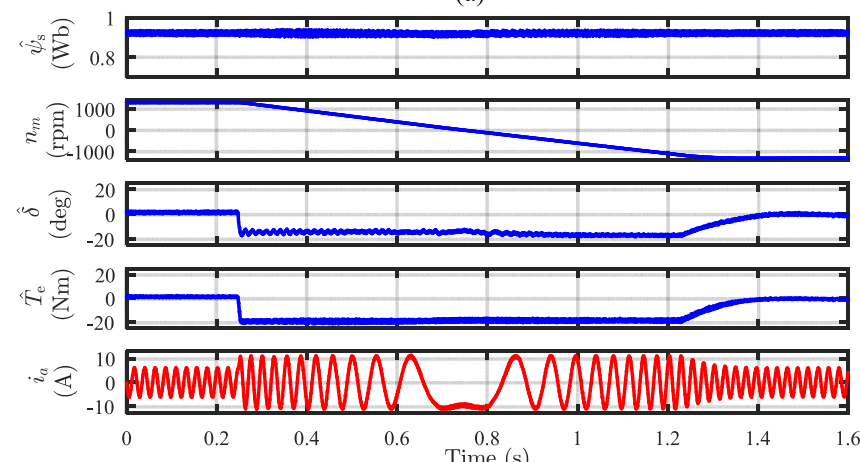

(b)

Fig. 10. Speed reversal maneuver with the SynRM operating at noload. From top to bottom: Stator flux, rotor speed, load angle, electromagnetic torque, and stator current waveform. (a) Simulation results. (b) Experimental test.

other alternative control approaches like DTC, demonstrating the very good steady-state performance of the proposed predictive control approach.

The second test carried out is a speed reversal maneuver from a speed of 1300 to $-1300 \mathrm{r} / \mathrm{min}$, with the SynRM initially operating at no-load (see Fig. 10).

The obtained results reveal that there is a decoupled control of the stator flux and electromagnetic torque developed by the SynRM. It is visible that the load angle and electromagnetic torque profiles are identical, which is an expected result as the stator flux level is fixed and set to the motor rated value. In general, we see that all simulation and experimental results agree very well.

To further assess the dynamic response of the proposed predictive control strategy, Figs. 11 and 12 show the obtained results for a torque step response from no-load to rated torque, at a speed of $700 \mathrm{r} / \mathrm{min}$. In this test, the SynRM drive is operated in torque control mode, by setting manually the value of the reference torque, while the auxiliary induction motor drive is operated in speed control mode in order to maintain the speed roughly constant during the test.

As can be seen, the torque response is very fast, as the drive only takes approximately $1.5 \mathrm{~ms}$ to increase the SynRM torque from no-load to the rated value $(19.1 \mathrm{~N} \cdot \mathrm{m})$.

As a whole, these results demonstrate that the excellent steady-state and dynamic responses of the proposed control system when the motor operates in the constant torque region.

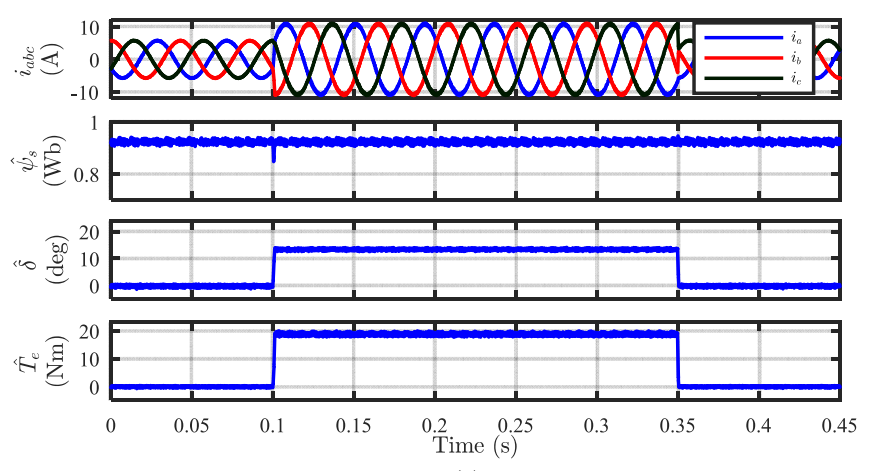

(a)
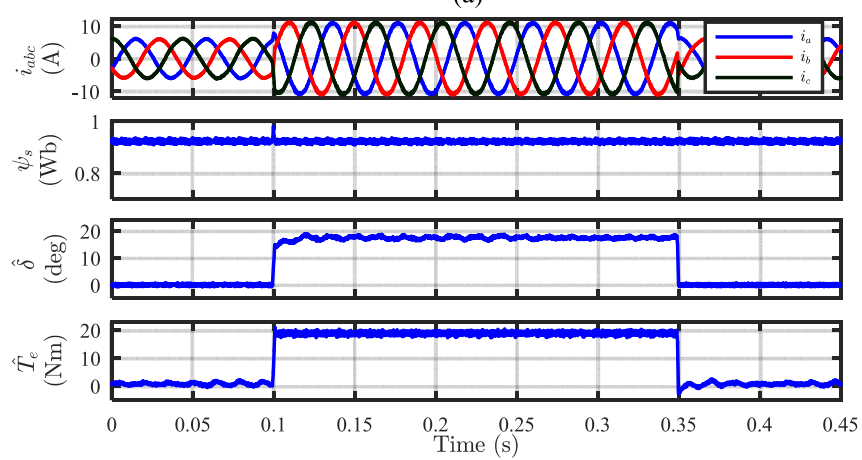

(b)

Fig. 11. Torque step response of the SynRM drive operating at 700 $\mathrm{r} / \mathrm{min}$. The torque step is $19.1 \mathrm{~N} \cdot \mathrm{m}$. (a) Simulation results. (b) Experimental test.

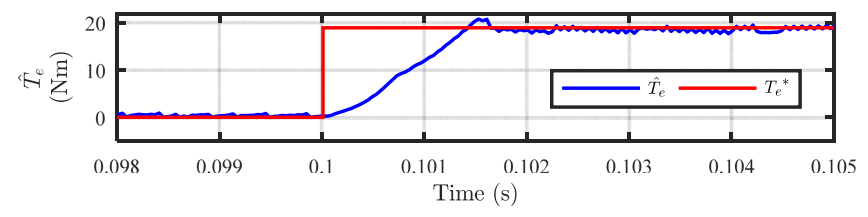

Fig. 12. Zoomed version of the torque step response shown in Fig $11(b)$, showing the variation of the reference torque and actual motor torque in the vicinity of $t=0.2 \mathrm{~s}$.

\section{B. FW Operation}

In this section, the drive is tested in the FW region to prove the ability of the control system to impose the current and voltage limitations as well as the load angle limitation (MTPV region), hence demonstrating the ability of the drive to operate at very high speeds, and ensuring the stability of the drive in the entire speed range.

In the tests here reported, the dc-link voltage was lowered to $190 \mathrm{~V}$, thus forcing the drive to enter into the FW region at 510 $\mathrm{r} / \mathrm{min}$.

The results obtained for the acceleration of the SynRM from 100 to $1280 \mathrm{r} / \mathrm{min}$ with a load torque of $6 \mathrm{~N} \cdot \mathrm{m}$ are shown in Figs. 13 and 14.

When the acceleration process is initiated, the motor develops the rated torque and draws the rated current. The drive is operating in region I as marked in Figs. 13 and 14. The rotor speed increases during the acceleration phase and so does the required voltage to maintain the stator flux constant at its rated value. With the increase of rotor speed, the voltage limit 


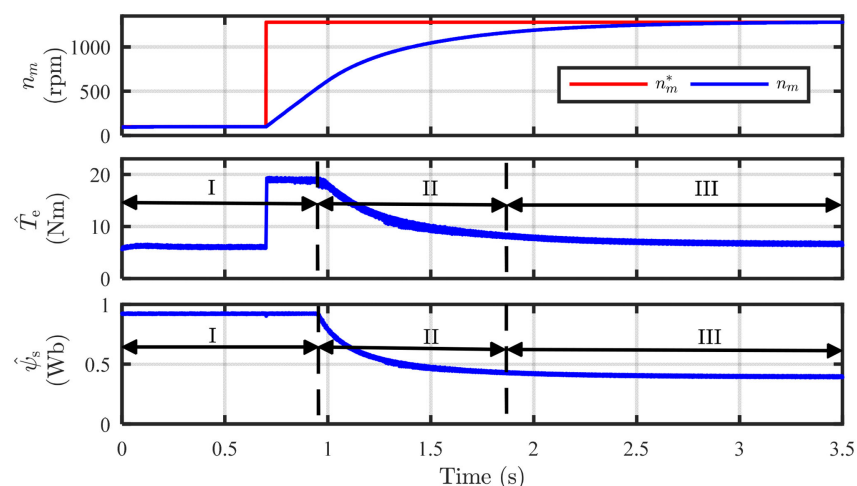

(a)
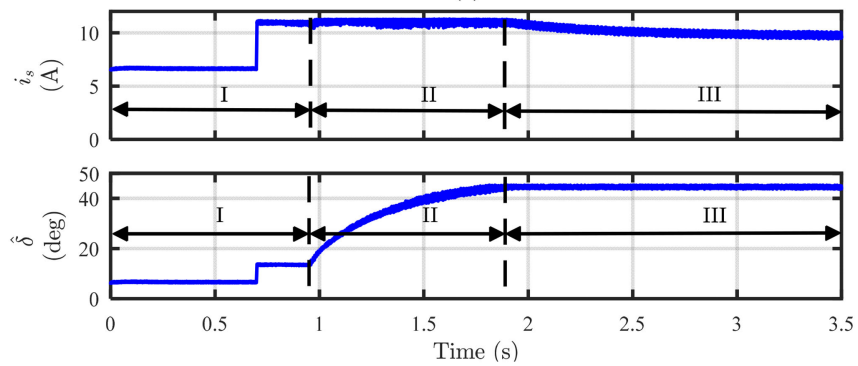

(b)

Fig. 13. Simulation results for the acceleration of the SynRM from 100 to $1280 \mathrm{r} / \mathrm{min}$, with a load torque of $6 \mathrm{~N} \cdot \mathrm{m}$. (a) Speed, torque, and stator flux waveforms. (b) Amplitude of the stator current and load angle.

imposed by the inverter is finally reached and, from this point on, the stator flux has to be decreased, forcing the drive to enter into FW operation. The drive now operates in region II, where the motor torque decreases with speed, while the current is maintained nearly at its rated value. On the other hand, in this region, the load angle increases until it reaches the limit of $45 \mathrm{deg}$. This is the point where the MTPV limit is reached, setting the beginning of region III. In this region, the current has to be decreased to respect the load angle limitation, leading to an accelerated reduction of the maximum torque the motor can develop in this high-speed region.

From the simulation and experimental results shown, it is clear that the proposed predictive control strategy ensures very stable and smooth transitions from region I to region II and from region II to region III, without the need of any elaborated controller tuning process.

\section{Optimal Stator Flux Level}

To demonstrate the increase of the SynRM efficiency when it operates with an optimal stator flux level, thus minimizing the stator copper losses for a given torque demand, some experimental tests were conducted at different torque reference values, for a speed of $700 \mathrm{r} / \mathrm{min}$. The motor efficiency was measured with the aid of the torque sensor and the precision power analyzer.

The obtained results are shown in Fig. 15.

As can be seen, the increase of the motor efficiency is higher for lower torque values, where the stator copper losses represent a higher percentage of the input power. For higher torque values,

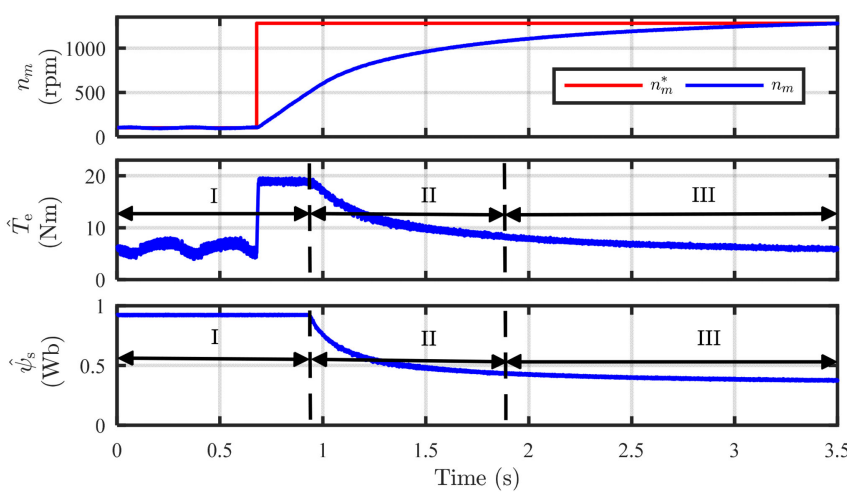

(a)
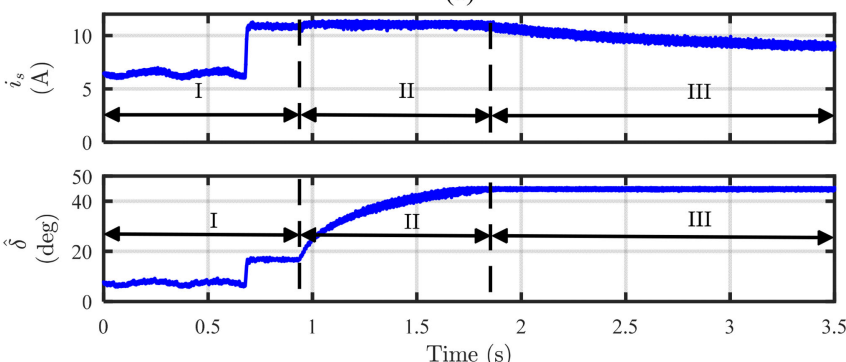

(b)

Fig. 14. Experimental results for the acceleration of the SynRM from 100 to $1280 \mathrm{r} / \mathrm{min}$, with a load torque of $6 \mathrm{~N} \cdot \mathrm{m}$. (a) Speed, torque, and stator flux waveforms. (b) Amplitude of the stator current and load angle.

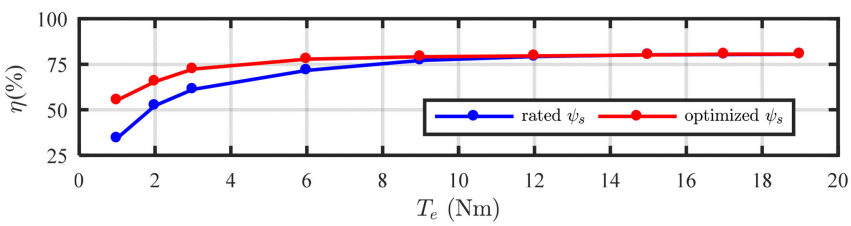

Fig. 15. SynRM efficiency with and without stator flux level optimization (SynRM running at $700 \mathrm{r} / \mathrm{min}$ ).

the gain in terms of motor efficiency is smaller, being null if the motor operates at rated torque.

A final remark to highlight that the implementation of the proposed control algorithm requires a relatively low computational effort, as the execution time in the digital control platform was around $30 \mu \mathrm{s}$, which can be considered a small value for a predictive control strategy.

\section{CONCLUSION}

A new simplified FCS-MPC strategy has been presented and successfully tested in this paper, through several simulations and experimental tests. The proposed control algorithm has several advantages compared to conventional schemes, such as the use of a simple cost function without any weighting factors to be tuned, and a smaller computational cost achieved by the simplification in the prediction stage of the proposed control algorithm. In addition, the control strategy retains the advantages of direct flux and load angle (torque) control. The transitions between the different regions of operation of the drive, including FW, are straightforward, ensuring at the same time a good torque dynamics. The MTPV limit is easily exploited due to the 
explicit prediction of the load angle, ending with a simple yet effective and powerful control strategy for SynRMs. The drive can operate at maximum dynamic performance, using the rated stator flux, or emulate the MTPA trajectory by setting the reference flux to an optimal level which minimizes the motor copper losses.

\section{REFERENCES}

[1] S. Taghavi and P. Pillay, "A sizing methodology of the synchronous reluctance motor for traction applications," IEEE J. Emerg. Sel. Topics Power Electron., vol. 2, no. 2, pp. 329-340, Jun. 2014.

[2] R. R. Moghaddam, F. Magnussen, and C. Sadarangani, "Theoretical and experimental reevaluation of synchronous reluctance machine," IEEE Trans. Ind. Electron., vol. 57, no. 1, pp. 6-13, Jan. 2010.

[3] E. Daryabeigi, H. A. Zarchi, G. R. A. Markadeh, J. Soltani, and F. Blaabjerg, "Online MTPA control approach for synchronous reluctance motor drives based on emotional controller," IEEE Trans. Power Electron., vol. 30, no. 4, pp. 2157-2166, Apr. 2015

[4] Y. Inoue, S. Morimoto, and M. Sanada, "A novel control scheme for maximum power operation of synchronous reluctance motors including maximum torque per flux control," IEEE Trans. Ind. Appl., vol. 47, no. 1, pp. 115-121, Jan./Feb. 2011.

[5] X. Zhang, G. H. B. Foo, D. M. Vilathgamuwa, and D. L. Maskell, “An improved robust field-weakeaning algorithm for direct-torque-controlled synchronous-reluctance-motor drives," IEEE Trans. Ind. Electron., vol. 62, no. 5, pp. 3255-3264, May 2015.

[6] S. Kouro, P. Cortes, R. Vargas, U. Ammann, and J. Rodriguez, "Model predictive control-A simple and powerful method to control power converters," IEEE Trans. Ind. Electron., vol. 56, no. 6, pp. 1826-1838, Jun. 2009.

[7] J. Rodriguez et al., "State of the art of finite control set model predictive control in power electronics," IEEE Trans. Ind. Informat., vol. 9, no. 2, pp. 1003-1016, May 2013.

[8] J. Riedemann, J. C. Clare, P. W. Wheeler, R. Blasco-Gimenez, M. Rivera, and R. Peña, "Open-end winding induction machine fed by a dual-output indirect matrix converter," IEEE Trans. Ind. Electron., vol. 63, no. 7, pp. 4118-4128, Jul. 2016.

[9] C. A. Rojas, J. Rodriguez, F. Villarroel, J. R. Espinoza, C. A. Silva, and M. Trincado, "Predictive torque and flux control without weighting factors," IEEE Trans. Ind. Electron., vol. 60, no. 2, pp. 681-690, Feb. 2013.

[10] M. Preindl and S. Bolognani, "Model predictive direct torque control with finite control set for PMSM drive systems, Part 1: Maximum torque per ampere operation," IEEE Trans. Ind. Informat., vol. 9, no. 4, pp. 1912 1921, Nov. 2013.

[11] J. Rodriguez, R. M. Kennel, J. R. Espinoza, M. Trincado, C. A. Silva, and C. A. Rojas, "High-performance control strategies for electrical drives: An experimental assessment," IEEE Trans. Ind. Electron., vol. 59, no. 2, pp. 812-820, Feb. 2012.

[12] R. Morales-Caporal and M. Pacas, "A predictive torque control for the synchronous reluctance machine taking into account the magnetic cross saturation," IEEE Trans. Ind. Electron., vol. 54, no. 2, pp. 1161-1167, Apr. 2007.

[13] R. Antonello, M. Carraro, L. Peretti, and M. Zigliotto, "Hierarchical scaled-states direct predictive control of synchronous reluctance motor drives," IEEE Trans. Ind. Electron., vol. 63, no. 8, pp. 5176-5185, Aug. 2016.

[14] C. K. Lin, J. t. Yu, Y. S. Lai, and H. C. Yu, "Improved model-free predictive current control for synchronous reluctance motor drives," IEEE Trans. Ind. Electron., vol. 63, no. 6, pp. 3942-3953, Jun. 2016.

[15] C. Lin, J. Yu, H. Yu, and Y. Lo, "Simplified model-free predictive current control for synchronous reluctance motor drive systems," in Proc. IEEE Magn. Conf., Beijing, China, 2015, p. 1.

[16] H. Hadla and S. Cruz, "Active flux based finite control set model predictive control of synchronous reluctance motor drives," in Proc. 18th Eur. Conf. Power Electron. Appl., Karlsruhe, Germany, 2016, pp. 1-10.

[17] J. Ahn, "Field weakening control of synchronous reluctance motor for electric power steering," IET Elect. Power Appl., vol. 1, pp. 565-570, 2007

[18] Y. Inoue, S. Morimoto, and M. Sanada, "Comparative study of PMSM drive systems based on current control and direct torque control in flux-weakening control region," IEEE Trans. Ind. Appl., vol. 48, no. 6, pp. 2382-2389, Nov./Dec. 2012.
[19] X. Zhang and G. H. B. Foo, "A robust field-weakening algorithm based on duty ratio regulation for direct torque controlled synchronous reluctance motor," IEEE/ASME Trans. Mechatronics, vol. 21, no. 2, pp. 1-10, Apr. 2016.

[20] G. Pellegrino, R. I. Bojoi, and P. Guglielmi, "Unified direct-flux vector control for AC motor drives," IEEE Trans. Ind. Appl., vol. 47, no. 5 , pp. 2093-2102, Sep./Oct. 2011.

[21] G. Pellegrino, E. Armando, and P. Guglielmi, "Direct-flux vector control of IPM motor drives in the maximum torque per voltage speed range," IEEE Trans. Ind. Electron., vol. 59, no. 10, pp. 3780-3788, Oct. 2012.

[22] B. Boazzo and G. Pellegrino, "Model-based direct flux vector control of permanent-magnet synchronous motor drives," IEEE Trans. Ind. Appl., vol. 51, no. 4, pp. 3126-3136, Jul./Aug. 2015.

[23] M. Preindl and S. Bolognani, "Model predictive direct torque control with finite control set for PMSM drive systems, Part 2: Field weakening operation," IEEE Trans. Ind. Informat., vol. 9, no. 2, pp. 648-657, May 2013.

[24] S. Vazquez et al., "Model predictive control: A review of its applications in power electronics," IEEE Ind. Electron. Mag., vol. 8, no. 1, pp. 16-31, Mar. 2014

[25] J. D. Barros, J. F. A. Silva, and É. G. A. Jesus, "Fast-predictive optimal control of NPC multilevel converters," IEEE Trans. Ind. Electron., vol. 60, no. 2, pp. 619-627, Feb. 2013.

[26] C. Xia, T. Liu, T. Shi, and Z. Song, "A simplified finite-control-set modelpredictive control for power converters," IEEE Trans. Ind. Informat., vol. 10, no. 2, pp. 991-1002, May 2014.

[27] G. Pellegrino, E. Armando, and P. Guglielmi, "Direct flux field-oriented control of IPM drives with variable DC link in the field-weakening region," IEEE Trans. Ind. Appl., vol. 45, no. 5, pp. 1619-1627, Sep./Oct. 2009.

[28] A. Imura, T. Takahashi, M. Fujitsuna, T. Zanma, and S. Doki, "Dead-time compensation in model predictive instantaneous-current control," in Proc. 38th Annu. Conf. IEEE Ind. Electron. Soc., 2012, pp. 5037-5042.

[29] M. Hinkkanen, T. Tuovinen, L. Harnefors, and J. Luomi, "A combined position and stator-resistance observer for salient PMSM drives: Design and stability analysis," IEEE Trans. Power Electron., vol. 27, no. 2, pp. 601-609, Feb. 2012.

[30] H. S. Hwan, J. Kim, H. Khang, and J. Ahn, "Parameter identification of a synchronous reluctance motor by using a synchronous PI current regulator at a standstill," J. Power Electron., vol. 10, pp. 491-497, 2010.

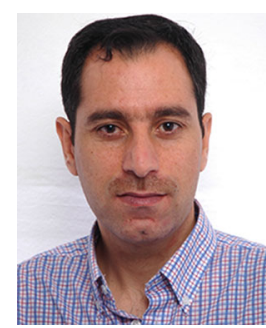

Hazem Hadla was born in Homs, Syria. He received the B.Sc. degree in electrical engineering from the University of Al-Baath, Homs, in 2007, and the M.Sc. degree in electrical machines from Cairo University, Giza, Egypt, in 2013. He is currently working towards the Ph.D. degree in electrical and computer engineering at the University of Coimbra, Coimbra, Portugal.

His research interests include electric drives and predictive control.

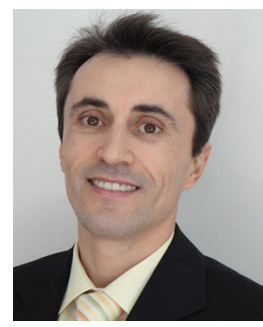

Sérgio Cruz (S'96-M'04-SM'16) received the Electrical Engineering diploma and the M.Sc., and Dr. Eng. degrees in electrical engineering from the University of Coimbra, Coimbra, Portugal, in 1994, 1999, and 2004, respectively.

$\mathrm{He}$ has been with the Department of Electrical and Computer Engineering, University of Coimbra, where he is currently an Assistant Professor and the Director of the Electric Machines Laboratory. His teaching and research interests include power transformers, rotating electric machines, electric drives, and power electronic converters, with special emphasis on fault diagnosis, fault tolerance, and digital control. He is the author of more than 80 journal and conference papers in his fields of research 